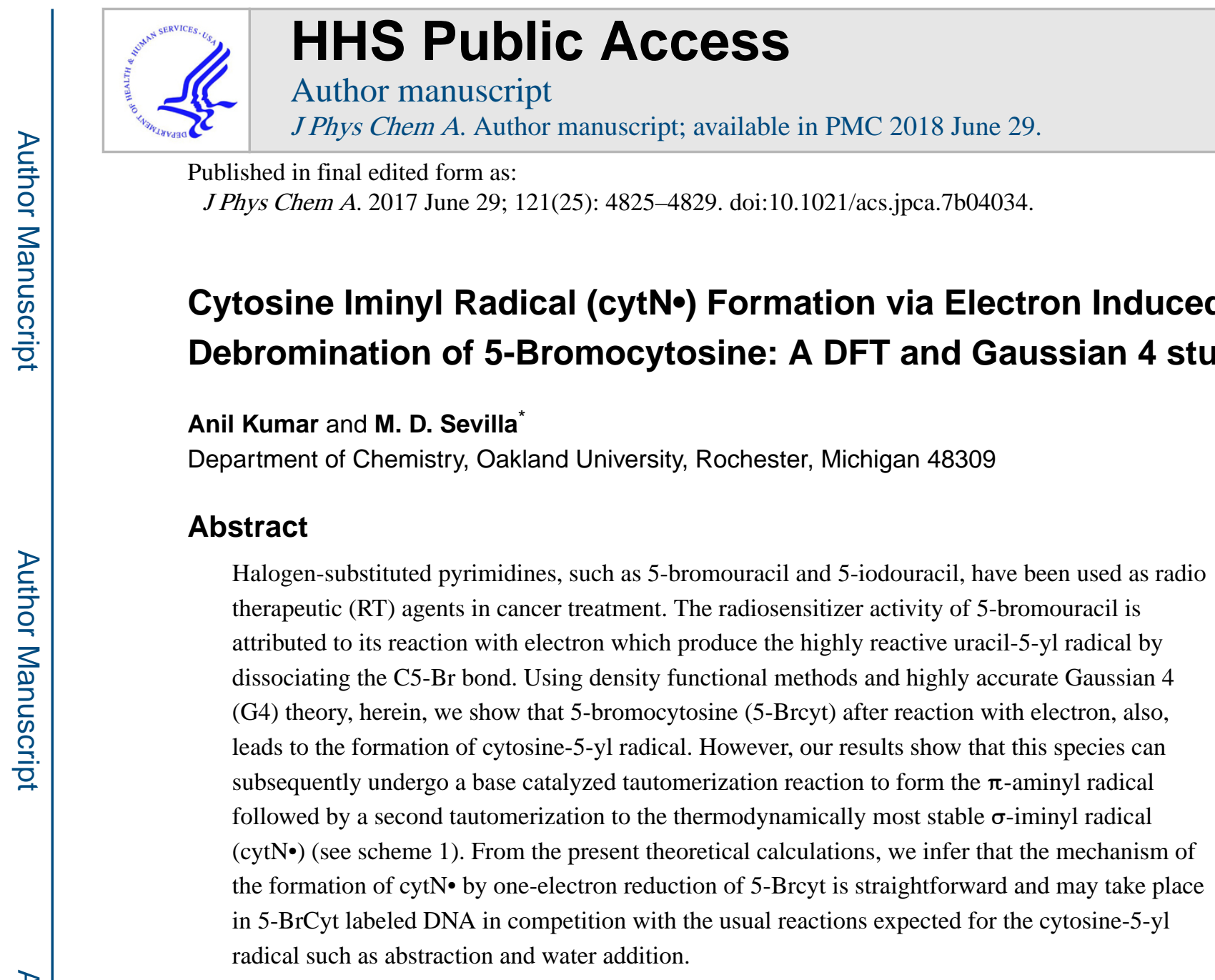

Graphical abstract

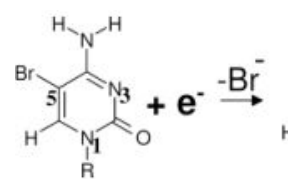

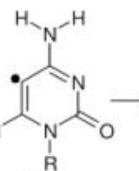

$(\sigma)$

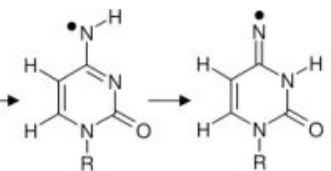

$(\pi)$

$(\sigma)$

$\mathrm{R}=\mathrm{CH}_{3} \quad$ cytosine-5-yl $\bullet \quad$ aminyl $\bullet \quad$ iminyl $\bullet$

\title{
Introduction
}

Halogen substituted nucleosides have long been studied as radiosensitizers with the goal of radio therapeutic (RT) treatment of cancer. ${ }^{1-9}$ Replacing thymine by 5 -halouracil (5-XU; $\mathrm{X}=$ $\mathrm{F}, \mathrm{Cl}, \mathrm{Br}$, and I) in cellular DNA leads to enhance the sensitivity to ionizing radiation (IR) and allows gene expression in unirradiated cells. . $^{3,2,4-8}$ Most studied is 5-Bromo-2'deoxyuridine (5-BrdU) as it has been found to sensitize hypoxic cancer cells to $\mathrm{IR}^{5,6,10,11}$

\footnotetext{
*Corresponding Author: sevilla@oakland.edu.

Associated Content

The Supporting Information contains: (a) Optimized geometries of 5-brcytosine in neutral and anion radical state, (b) HOMO and LUMO of 5-bromocytosine, (c) Enlarged view of figures 1-3, (d) Potential energy surfaces for proton transfer reactions and (e) complete Gaussian 09 reference. The Supporting Information is available free of charge on the ACS Publications website. 
and has been employed as a radiosensitizer in clinical trials, although, little survival advantage was reported. ${ }^{12}$ 5-Bromo-2'-deoxycytidine has also been tested for its radiosensitization activity in cancer cell lines. ${ }^{9}$

The enhanced radiosensitization activity of 5-BrdU in DNA has been proposed to involve its reaction with radiation produced electrons. The 5-BrdU anion radical ( $\pi$-type) formed converts to a weakly bond ( $\sigma$-type) anion radical which subsequently dissociates into uracil-5-yl radical ( $\sigma$-type) and bromide ion $\left(\mathrm{Br}^{-}\right){ }^{4,5,13-18}$ The uracil-5-yl ${ }^{\bullet}$ is highly reactive and is suggested to abstract a hydrogen atom from $\mathrm{C}_{1^{\prime}}$ or $\mathrm{C}_{2^{\prime}}$ site of the adjacent deoxyribose which ends up with DNA strand breaks. ${ }^{4,5,15,18}$. Li et al note that 5 -BrdU in double stranded DNA is less electron affinic than in single stranded DNA which would make 5-BrdU selective for replicating DNA. ${ }^{19}$ Electron spin resonance (ESR) work has shown that other reactions occur after electron addition to 5 -BrdU, for example, the $\pi$-anion radical is shown to protonate at $\mathrm{C} 6$ to form a $\mathrm{C} 5$ radical $\left(6,6\right.$ dihydro-5-bromouracyl-5-yl $\left.{ }^{\circ}\right)$ under certain conditions. ${ }^{20}$ Water addition to the uracil-5-yl ${ }^{\bullet}$ at the $\mathrm{C} 5$ site has been found to form the 5hydroxy-5-hydro-uracyl-6-yl radical. ${ }^{13}$ Very recently, ESR and density functional theory (DFT) studies demonstrated that the reaction of uracil-5-yl ${ }^{\bullet}$ with water may produce $\mathrm{OH}^{\bullet}$ as an intermediate which may lead to strand breaks. ${ }^{17}$ Interestingly, photochemical formation of uracil-5-yl ${ }^{\bullet}$ in 5 -XU containing DNA is used to probe the structure of DNA. ${ }^{4}$

Here, ab initio quantum chemical methods are employed to investigate the reaction of radiation produced electrons with 5-bromocytosine (5-Brcyt). These theoretical predictions clearly show that one-electron reduction of 5-Brcyt leads to the formation of $\pi$-type 5-Brcyt anion radical (I) which subsequently dissociates into a reactive $\sigma$-type cytosine-5-yl (IIa) and bromide ion. The $\sigma$-type cytosine-5-yl ${ }^{\bullet}$ undergoes a tautomerization reaction which transfers a hydrogen from $\mathrm{NH} 2$ group to $\mathrm{C} 5$ atom of cytosine to produce a $\pi$-type aminyl radical (cytNH ${ }^{*}$ ) (III) which tautomerizes again by transferring hydrogen from $\mathrm{NH}$ to $\mathrm{N} 3$ of cytosine to form the more stable $\sigma$-type iminyl radical (cytN•) (IV) as shown in Scheme 1. The latter step (III to IV) has been shown by both pulse radiolysis and ESR experiments in which cytosine underwent one-electron oxidation. ${ }^{21,22}$ This reaction is also supported by theory. ${ }^{21,22}$ However, the chemistry induced by one-electron reduction of 5-Brcyt to form the iminyl radical (cytN•) by a double tautomerization mechanism is novel and predicted in this work.

\section{Methods of Calculation}

In the present study, we used B3LYP, $\omega \mathrm{b} 97 \mathrm{X}$ and M06-2X DFT methods with 6-31++G(d, p) basis set to calculate the relative stabilities of 5 -Brcyt ${ }^{--}$, cytosine-5-yl ${ }^{\circ}$, aminyl radical $\left(\mathrm{cytNH}^{\circ}\right)$ and iminyl radical (cytN•), shown in Scheme 1, by calculating their free energies in aqueous phase via the integral equation formalism of the polarized continuum model (IEF-PCM) of Tomasi et al. ${ }^{23}$ Geometry of each species was fully optimized by each of the DFT method mentioned above. Using optimized geometries, thermodynamics followed by frequency calculation was done to obtain the free energy $(\Delta \mathrm{G})$ of each species. The vibrational frequencies of each species were found to be positive which ensure the occurrence of these species. All these DFT methods support the formation of the most stable iminyl radical (cytN•) via stepwise tautomerization of cytosine-5-yl. The free energy barrier 
height for reaction 5-Brcyt ${ }^{-} \rightarrow$ cytosine-5-yl ${ }^{\bullet}+\mathrm{Br}^{-}$in aqueous phase were also calculated by these DFT methods with $6-31++\mathrm{G}(\mathrm{d}, \mathrm{p})$ basis set.

These DFT predictions were further supported by high level ab initio-based Gaussian 4 (G4) level of calculation including IEF-PCM. The G4 theory is a combination of several electron correlated ab initio methods for accurate prediction of thermodynamic properties ${ }^{24-26}$ of molecules developed by Curtiss et al. ${ }^{24}$ The average absolute deviation in energies calculated at the G4 level including enthalpies, ionization energies, electron affinities, proton affinities, and hydrogen bond complexes for a data set of 454 experimental values is 0.83 $\mathrm{kcal} / \mathrm{mol}$ and the root-mean-square deviation is $1.19 \mathrm{kcal} / \mathrm{mol}{ }^{24}$ The details of the G4 theory is described elsewhere. ${ }^{24}$ All calculations were performed using Gaussian 09 suites of program. ${ }^{27}$ To mimic the effect of sugar moiety, methyl $\left(\mathrm{CH}_{3}\right)$ group is attached to the N1 site of the cytosine, see scheme 1 .

\section{Results and Discussion}

\section{Debromination reaction}

The ESR studies at low temperature has shown that brominated-bases in DNA serves as efficient electron trap due to their high electron affinity in comparison to the canonical DNA bases. ${ }^{14}$ Even in DNA the brominated-radical anions are found. ${ }^{13}$ Our DFT calculations show that the adiabatic electron affinity (AEA) of 5-Brcyt predicted by the G4 level of theory and by the other DFT methods lie in the range $2.16-2.27 \mathrm{eV}$, see Table 1, which is in agreement with recent study by Chomicz et al. ${ }^{28}$. Theory and experiment have shown that $\mathrm{C} 5-\mathrm{Br}$ bond of the 5-bromouracil radical anion is quite weak and dissociates into $\mathrm{Br}^{-}$and uracil-5-yl. 4,5,17,28,29

In this study the reaction, 5-Brcyt ${ }^{--} \rightarrow$ cytosine-5-yl ${ }^{\bullet}+\mathrm{Br}^{-}$, is studied using the B3LYP$\mathrm{PCM} / 631++\mathrm{G}(\mathrm{d}, \mathrm{p})$ method. The potential energy surface (PES) of $\mathrm{C} 5-\mathrm{Br}$ bond dissociation of 5-Brcyt ${ }^{-}-$is shown in Figure 1. In Figure 1, the nature of the singly occupied molecular orbital (SOMO) is also shown at each step of the reaction. We found that in 5-Brcyt ${ }^{\circ-}$ (reactant), SOMO is delocalized on the cytosine ring as $\pi$-type. The transition state (TS) is a mixed $\sigma-\pi$ state with the SOMO localized on the $\mathrm{Br}$ atom as the $\sigma$-state and delocalized on the cytosine base as the $\pi$-state as reported in earlier work on $5 \mathrm{BrU}$ by Sevilla and coworkers. ${ }^{29}$ As the $\mathrm{C}$-Br bond length increases a loosely bound metastable $\sigma$ radical mainly localized to the $\mathrm{C}$-Br bond (II) is formed (see Figure 1) (This species is observed in DNA containing Br-Cyt by ESR) ${ }^{14}$. On complete $\mathrm{C} 5$-Br bond dissociation (product, IIa), the radical formed shows the localization of spin density mainly on C5 atom (Figure 2) which characterizes it as $\sigma$-cytosine-5-yl radical (IIa). The free energy barrier height for C5$\mathrm{Br}$ bond dissociation of 5-Brcyt ${ }^{--}$by the B3LYP-PCM/6-31++G(d,p) method is calculated as $1.8 \mathrm{kcal} / \mathrm{mol}$ having one imaginary frequency $\left(-351 \mathrm{~cm}^{-1}\right)$ characterizing the transition state, see Figure 1. This is almost identical to the barrier found for 5-bromouracil of 1.9 $\mathrm{kcal} / \mathrm{mol}$ found by $\mathrm{Li}$ et al in the gas phase using B3LYP/6-31+G(d) method. ${ }^{19}$ On complete dissociation of the $\mathrm{C} 5-\mathrm{Br}$ bond of $5-\mathrm{Brcyt}^{--}$, the product (cytosine-5-yl ${ }^{\bullet}$ and $\mathrm{Br}^{-}$) is found to be thermodynamically more stable than the reactant $\left(5-\mathrm{Brcyt}^{\circ}\right)$ by $15 \mathrm{kcal} / \mathrm{mol}$, see Figure 1. The present calculation shows that electron addition to 5-Brcyt leads to spontaneous C5$\mathrm{Br}$ bond dissociation to produce cytosine-5-yl ${ }^{\circ}$ and bromide ion. In the gas phase, the 
calculations performed by Li et al. ${ }^{19}$ for 5-bromouracil anion radical show a large energy barrier $(21 \mathrm{kcal} / \mathrm{mol})$ for complete separation to "infinity" of the uracil-5-yl radical and bromide ion. This shows that solvation is the driving force for the full cleavage of the C-Br bond after electron attachment.

The potential energy surfaces (PES) for the tautomerizaton reactions from the $\mathrm{NH}_{2}$ group of cytosine-5-yl ${ }^{\bullet}$ (IIa) to form the intermediate aminyl radical (III) and finally the iminyl radical (IV) were calculated using the B3LYP-PCM/6-31++G(d, p) level of theory in the presence of four water molecules including full aqueous phase via PCM. The complete results are presented in the supporting information. The barriers found for the tautomerization reactions from IIa to III and from III to IV were found to be high (24 $\mathrm{kcal} / \mathrm{mol}$ and $18 \mathrm{kcal} / \mathrm{mol}$, see Figure S7). These calculated barrier heights are large likely owing to the small size of the solvation layer considered. We note that the tautomerization of the aminyl radical (III) to produce the iminyl radical (IV) has been shown experimentally by ESR to occur even at low temperatures of $160 \mathrm{~K}$ (suggesting a barrier of $<3 \mathrm{kcal} / \mathrm{mol}$ ), as well as, by pulse radiolysis experiments at room temperature. ${ }^{21,22}$ Thus the experimental barrier appears to be far lower than the calculated value of $18 \mathrm{kcal} / \mathrm{mol}$. These experiments further showed that the tautomerization of aminyl radical (III) to produce iminyl radical (IV) was base catalyzed. ${ }^{21,22}$ We therefore investigated a model for the tautomerization from IIa to III in which an hydroxide anion was present in place of a water and solvated by two water molecules, see Figure S8 in the supporting information. In this case, the barrier was substantially reduced and proton transfer from $\mathrm{NH}_{2}$ group of cytosine-5-yl' (IIa) to hydroxide anion takes place with negligible barrier ( $\mathrm{ca} .0 .3 \mathrm{kcal} / \mathrm{mol}$ ) by producing an intermediate surrounded by three water molecules, see Figure S8 in the supporting information. From this intermediate the proton transfer from a water molecule hydrogenbonded to C5 to produce aminyl radical (III) proceeds via a barrier of ca. $5 \mathrm{kcal} / \mathrm{mol}$. The present calculation shows that the tautomerization of cytosine-5-yl (IIa) to form iminyl radical (IV) is favorable in an basic environment. The details for the transition state search are described in the supporting information.

\section{G4 Calculations of the Tautomerization of cytosine-5-yl'}

In contrast to the chemistry of 5-bromouracil radical anion which is well known to produce highly reactive uracil-5-yl ${ }^{\bullet}$, the present study shows that the chemistry of 5-bromocytosine radical anion does first lead to the formation of cytosine-5-yl, however, this species then tautomerizes to the thermodynamically more stable $\pi$-type aminyl radical (III) then tautomerizes to $\sigma$-type iminyl radical (IV) as shown in Scheme 1. Using the G4 level of theory and the chosen DFT methods, we calculated the relative stabilities of the different tautomers (III and IV) of cytosine-5-yl ${ }^{*}$ (IIa) shown in Scheme 1 and Figure 2. In this work, we considered the different tautomers of cytosine-5-yl ${ }^{*}$ by transferring a hydrogen atom of $\mathrm{NH}_{2}$ group either to the $\mathrm{C} 5$ or the $\mathrm{N} 3$ sites of cytosine ring and calculated their stabilities by G4 and the other DFT methods with respect to cytosine-5-yl (IIa), see Figure 2 and Table 1. We found that transfer of one hydrogen atom from the $\mathrm{NH}_{2}$ group can be made to the $\mathrm{C} 5$ site or the N3 site to produce radicals III and IIIa shown in Figure 2. The G4 and DFT methods predicted structure III to be more stable than IIIa by over $30 \mathrm{kcal} / \mathrm{mol}$, see Table 1 . In addition, structure III is more stable than the cytosine-5-yl (IIa) by ca. $9 \mathrm{kcal} / \mathrm{mol}$ at G4 
level of theory (Table 1). Further, this aminyl radical (cytNH ${ }^{\bullet}$ (III)) transfers the remaining hydrogen atom from $\mathrm{NH}$ to the open $\mathrm{N} 3$ site to produce $\sigma$-type iminyl radical (cytN $\mathrm{N}^{\bullet}$ (IV)) which is the most stable tautomer. The iminyl radical (cytN ${ }^{\bullet}$ (IV)) is $13 \mathrm{kcal} / \mathrm{mol}$ (G4 level of theory) more stable that the parent cytosine-5-yl' (IIa), see Table 1 . The overall relative stability of 5-Brcyt after electron attachment and occurrence of different tautomers, calculated by G4 level of theory in aqueous phase, is shown in Figure 3. From Figure 3, it is evident that electron attachment to neutral 5-Brcyt leads to 5-Brcyt ${ }^{\circ-}$ formation (I) which reacts through a metastable $\sigma$-type intermediate (II) (not shown in Figure 3) which dissociates into cytosine-5-yl (IIa) and $\mathrm{Br}^{-}$, the resulting cytosine-5-yl ${ }^{\bullet}$ is further stabilized by tautomerization to III by $\mathrm{N}-\mathrm{H}$ transfer to $\mathrm{C} 5$ and a second $\mathrm{N}-\mathrm{H}$ tautomerization to $\mathrm{N} 3$ to form the $\sigma$-iminyl radical (cytN ${ }^{\bullet}$ (IV)).

\section{Conclusions}

We report here a mechanism for the formation of the cytosine $\sigma$-iminyl radical IV (cytN") by a reductive process starting with 5-bromocytosine. One-electron oxidation of cytosine was earlier investigated using EPR and pulse radiolysis experiments. ${ }^{21,22,30,31}$ These studies report the formation of the $\pi$-aminyl radical (cytNH ${ }^{*}$ (III)) and its subsequent tautomerization to form the $\sigma$-iminyl radical IV $(\mathrm{cytN} \bullet)$. Anderson et al. ${ }^{31}$ proposed the formation of $\sigma$-iminyl radical $\mathrm{IV}\left(\mathrm{cytN}^{*}\right)$ by selective one-electron oxidation of cytosine with selenite radical in calf thymus DNA. This species (cytN $\left.{ }^{*}\right)$ then oxidized the hydrogenbonded guanine in DNA. It is noted that in DNA, high energy radiation directly produces the guanine cation radical because ionizations at other bases undergo hole transfer to guanine which has the lowest IP of all the DNA bases. Thus, if the $\sigma$-type iminyl radical IV (cytN•) was formed in DNA by electron addition to 5Brcyt it would likely form one-electron oxidized guanine as proposed by Anderson et al. ${ }^{31}$ Thus, 5 -Brcyt labeling in DNA has an important implication as it can convert a relatively benign reducing agent, the solvated electron, to a series of reactive oxidizing radicals (IIA, III, IV) which ultimately would increase the formation of guanine cation radical. Thus, this mechanism has the potential to significantly increase oxidative damage in irradiated DNA.

\section{Supplementary Material}

Refer to Web version on PubMed Central for supplementary material.

\section{Acknowledgments}

We thank the National Cancer Institute of the National Institutes of Health (grant R01CA045424) for support. We are also thankful to Research Excellence Fund (REF) and Center for Biomedical Research (CBR) at Oakland University for support.

\section{References}

1. Rupp WD, Prusoff WH. Incorporation of 5-Iodo-2' -Deoxyuridine into Bacteriophage T1 as Related to Ultra-Violet Sensitization or Protection. Nature. 1964; 202:1288-1290. [PubMed: 14210956]

2. Dewey WC, Sedita BA, Humphrey RM. Radiosensitization of X Chromosome of Chinese Hamster Cells Related to Incorporation of 5-Bromodeoxyuridine. Science. 1966; 152:519-521. [PubMed: 5910191] 
3. Howard-Flanders P, Boyce RP, Theriot L. Mechanism of Sensitization to Ultra-Violet Light of T1 Bacteriophage by the Incorporation of 5-Bromodeoxyuridine or by Pre-Irradiation of the Host Cell. Nature. 1962; 195:51-54. [PubMed: 14449373]

4. Xu Y, Sugiyama H. Photochemical Approach to Probing Different DNA Structures. Angew. Chem. Int. Ed. 2006; 45:1354-1362.

5. Tashiro, R., Sugiyama, H. Reactivity of 5-Halopyrimidines in Nucleic Acids. In: Greenberg, MM., editor. Radical and Radical Ion Reactivity in Nucleic Acid Chemistry. John Wiley \& Sons, Inc.; 2009. p. 163-189.

6. Cecchini S, Girouard S, Huels MA, Sanche L, Hunting DJ. Single-Strand-Specific Radiosensitization of DNA by Bromodeoxyuridine. Radiat. Res. 2004; 162:604-615. [PubMed: 15548110]

7. Shewach, DS., Lawrence, TS. Nucleoside Radiosensitizers. In: Peters, GJ., editor. Deoxynucleoside Analogs In Cancer Therapy. Cancer Drug Discovery and Development; Humana Press; 2006. p. 289-329.

8. Kummar S, Anderson L, Hill K, Majerova E, Allen D, Horneffer Y, Ivy SP, Rubinstein L, Harris P, Doroshow JH, et al. First-in-Human Phase 0 Trial of Oral 5-Iodo-2-Pyrimidinone-2'-Deoxyribose in Patients with Advanced Malignancies. Clin. Cancer Res. 2013; 19:1852-1857. [PubMed: 23403637]

9. Lawrence TS, Davis MA. Selective Radiosensitization and Cytotoxicity of Human Melanoma Cells Using Halogenated Deoxycytidines and Tetrahydrouridine. Int. J. Radiat. Oncol. 1989; 16:12431246.

10. Lawrence TS, Davis MA, Maybaum J, Stetson PL, Ensminger WD. The Effect of Single versus Double-Strand Substitution on Halogenated Pyrimidine-Induced Radiosensitization and DNA Strand Breakage in Human Tumor Cells. Radiat. Res. 1990; 123:192-198. [PubMed: 2389005]

11. Kinsella TJ, Dobson PP, Mitchell JB, Fornace AJ. Enhancement of X Ray Induced DNA Damage by Pre-Treatment with Halogenated Pyrimidine Analogs. Int. J. Radiat. Oncol. 1987; 13:733-739.

12. Lehnert, S. Radiosensitizers and Radiochemotherapy in the Treatment of Cancer. CRC Press; 2014.

13. Sevilla MD, Failor R, Zorman G. Radicals Formed after Electron Attachment to 5-Halouracils in Aqueous Glasses. J. Phys. Chem. 1974; 78:696-699.

14. Razskazovskii Y, Swarts SG, Falcone JM, Taylor C, Sevilla MD. Competitive Electron Scavenging by Chemically Modified Pyrimidine Bases in Bromine-Doped DNA: Relative Efficiencies and Relevance to Intrastrand Electron Migration Distances. J. Phys. Chem. B. 1997; 101:1460-1467.

15. Wiczk J, Miloch J, Rak J. UV-Induced Strand Breaks in Double-Stranded DNA Labeled with 5Bromouracil: Frank or Secondary? J. Phys. Chem. Lett. 2013; 4:4014-4018.

16. Rak J, Chomicz L, Wiczk J, Westphal K, Zdrowowicz M, Wityk P, Żyndul M, Makurat S, Golon Ł. Mechanisms of Damage to DNA Labeled with Electrophilic Nucleobases Induced by Ionizing or UV Radiation. J. Phys. Chem. B. 2015; 119:8227-8238. [PubMed: 26061614]

17. Chomicz L, Petrovici A, Archbold I, Adhikary A, Kumar A, Sevilla MD, Rak J. An ESR and DFT Study of Hydration of the 2'-Deoxyuridine-5-Y1 Radical: A Possible Hydroxyl Radical Intermediate. Chem Commun. 2014; 50:14605-14608.

18. Chen T, Cook GP, Koppisch AT, Greenberg MM. Investigation of the Origin of the Sequence Selectivity for the 5-Halo-2'-Deoxyuridine Sensitization of DNA to Damage by UV-Irradiation. J. Am. Chem. Soc. 2000; 122:3861-3866.

19. Li X, Sevilla MD, Sanche L. DFT Investigation of Dehalogenation of Adenine-Halouracil Base Pairs upon Low-Energy Electron Attachment. J. Am. Chem. Soc. 2003; 125:8916-8920. [PubMed: 12862488]

20. Haindl E, Hüttermann J. An a-Bromo Radical in X-Irradiated Single Crystals of 5Bromodeoxyuridine. J. Magn. Reson. 1969. 1978; 30:13-25.

21. Naumov S, Hildenbrand K, von Sonntag C. Tautomers of the N-Centered Radical Generated by Reaction of SO4- with N1-Substituted Cytosines in Aqueous Solution. Calculation of Isotropic Hyperfine Coupling Constants by a Density Functional Method. J. Chem. Soc. Perkin Trans 2. 2001; (9):1648-1653. 
22. Adhikary A, Kumar A, Bishop CT, Wiegand TJ, Hindi RM, Adhikary A, Sevilla MD. $\pi$-Radical to $\sigma$-Radical Tautomerization in One-Electron-Oxidized 1-Methylcytosine and Its Analogs. J. Phys. Chem. B. 2015; 119:11496-11505. [PubMed: 26237072]

23. Tomasi J, Mennucci B, Cammi R. Quantum Mechanical Continuum Solvation Models. Chem. Rev. 2005; 105:2999-3094. [PubMed: 16092826]

24. Curtiss LA, Redfern PC, Raghavachari K. Gaussian-4 Theory. J. Chem. Phys. 2007; 126:84108.

25. Kumar A, Adhikary A, Shamoun L, Sevilla MD. Do Solvated Electrons $\left(\mathrm{E}_{\mathrm{aq}}{ }^{-}\right.$) Reduce DNA Bases? A Gaussian 4 and Density Functional Theory- Molecular Dynamics Study. J. Phys. Chem. B. 2016; 120:2115-2123. [PubMed: 26878197]

26. Kumar A, Walker JA, Bartels DM, Sevilla MD. A Simple Ab Initio Model for the Hydrated Electron That Matches Experiment. J. Phys. Chem. A. 2015; 119:9148-9159. [PubMed: 26275103]

27. Frisch, MJ., Trucks, GW., Cheeseman, JR., Scalmani, G., Caricato, M., Hratchian, HP., Li, X., Barone, V., Bloino, J., Zheng, G., et al. Gaussian 09. Gaussian Inc.; Wallingford CT: 2009.

28. Chomicz L, Golon Ł, Rak J. The Radiosensitivity of 5- and 6-Bromocytidine Derivatives Electron Induced DNA Degradation. Phys. Chem. Chem. Phys. 2014; 16:19424. [PubMed: 25102433]

29. Li X, Sanche L, Sevilla MD. Dehalogenation of 5-Halouracils after Low Energy Electron Attachment: A Density Functional Theory Investigation. J. Phys. Chem. A. 2002; 106:1124811253.

30. Geimer J, Hildenbrand K, Naumov S, Beckert D. Radicals Formed by Electron Transfer from Cytosine and 1-Methylcytosine to the Triplet State of Anthraquinone-2,6-Disulfonic Acid. A Fourier-Transform EPR Study. Phys. Chem. Chem. Phys. 2000; 2:4199-4206.

31. Anderson RF, Shinde SS, Maroz A. Cytosine-Gated Hole Creation and Transfer in DNA in Aqueous Solution. J. Am. Chem. Soc. 2006; 128:15966-15967. [PubMed: 17165712] 


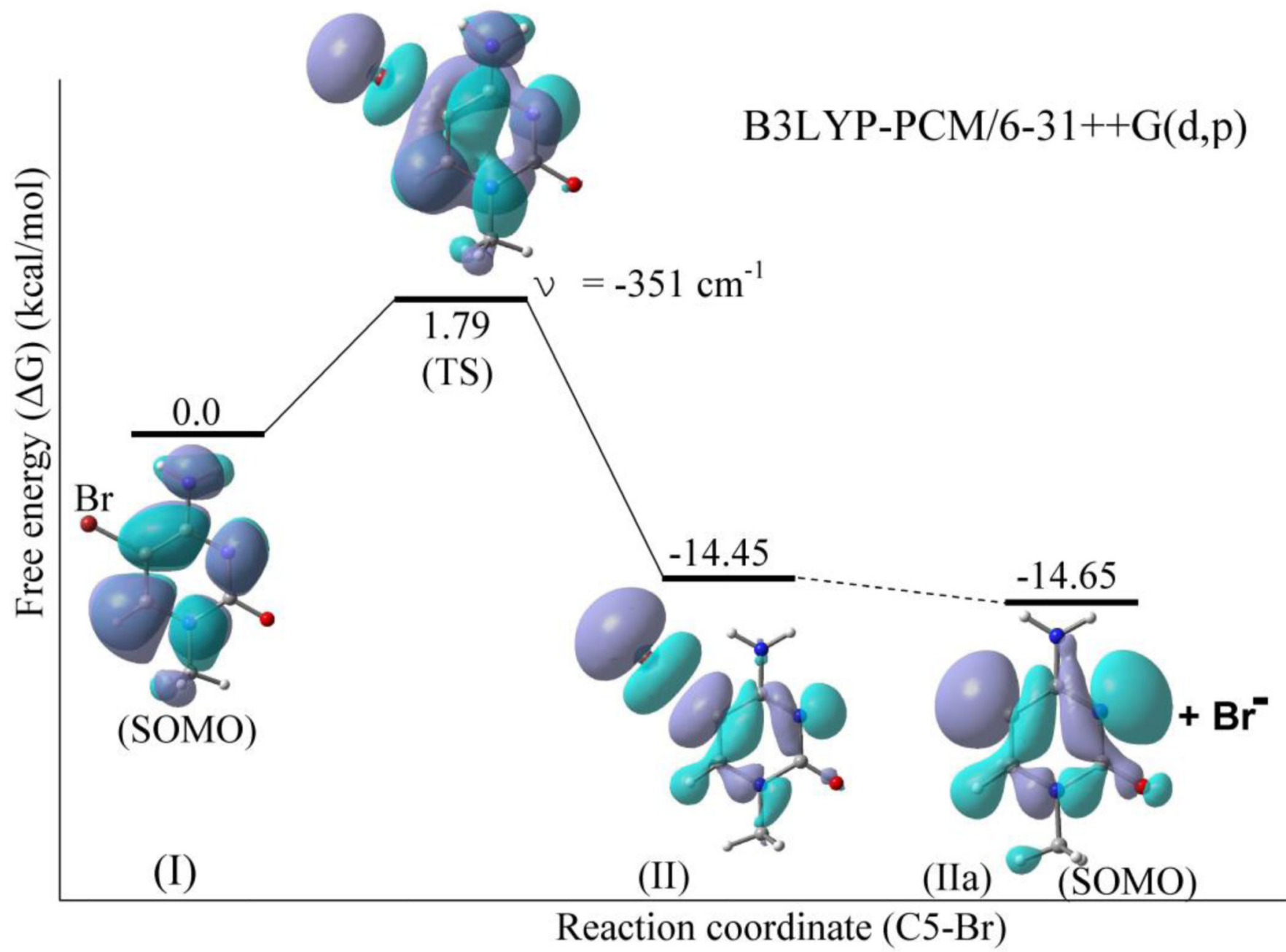

Figure 1.

Free energy $(\Delta \mathrm{G})$ reaction profile of 5-BrCyt ${ }^{-} \rightarrow \mathrm{Br}^{-}+$cytosine-5-yl $\bullet$ computed at the B3LYP/6-31++G(d,p) level in water using PCM solvation model. Energies are given in kcal/ mol. $\mathrm{TS}=$ Transition state characterized by one negative frequency. 


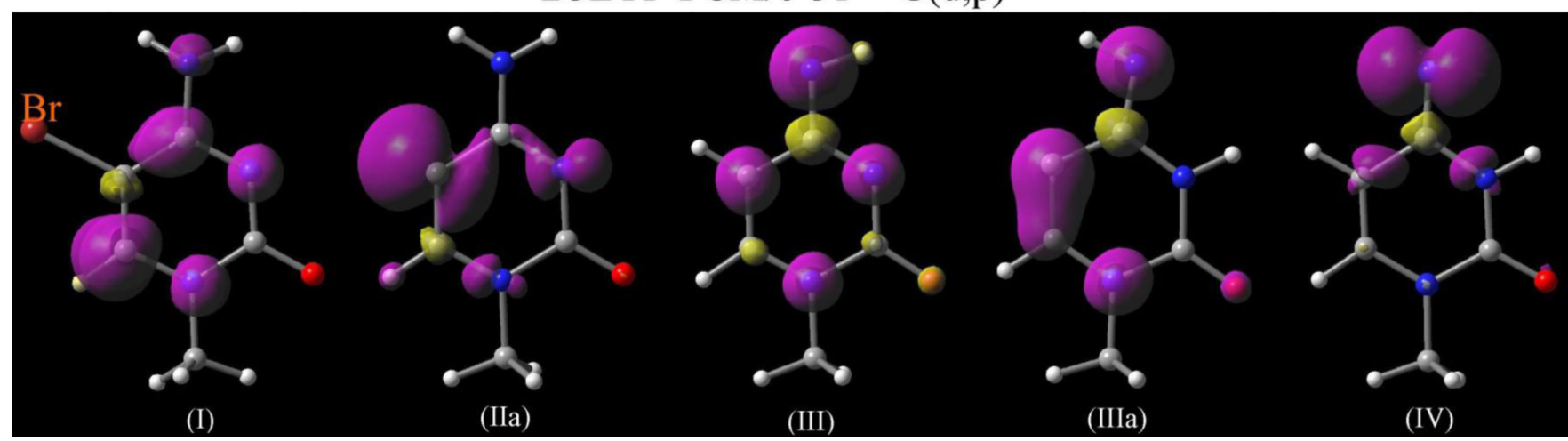

Figure 2.

Spin density plot of (I) 5 -BrCyt ${ }^{-}$( $\pi$-type), (IIa) cytosine-5-yl ${ }^{\bullet}(\sigma$-type), (III) aminyl radical (cytNH ${ }^{\circ}, \mathrm{H}$-shift to C5) ( $\pi$-type), (IIIa) aminyl radical (cytNH ${ }^{\circ}, \mathrm{H}$-shift to N3) ( $\pi$-type) and (IV) iminyl radical (cytN•) (( $\sigma$-type)). The spin density distributions are calculated by B3LYP-PCM/6-31++G(d,p) method. Radical (III) is over $30 \mathrm{kcal} / \mathrm{mol}$ more stable than its tautmer (IIIa) at G4, see Table 1. Species are numbered as shown in Scheme 1. 


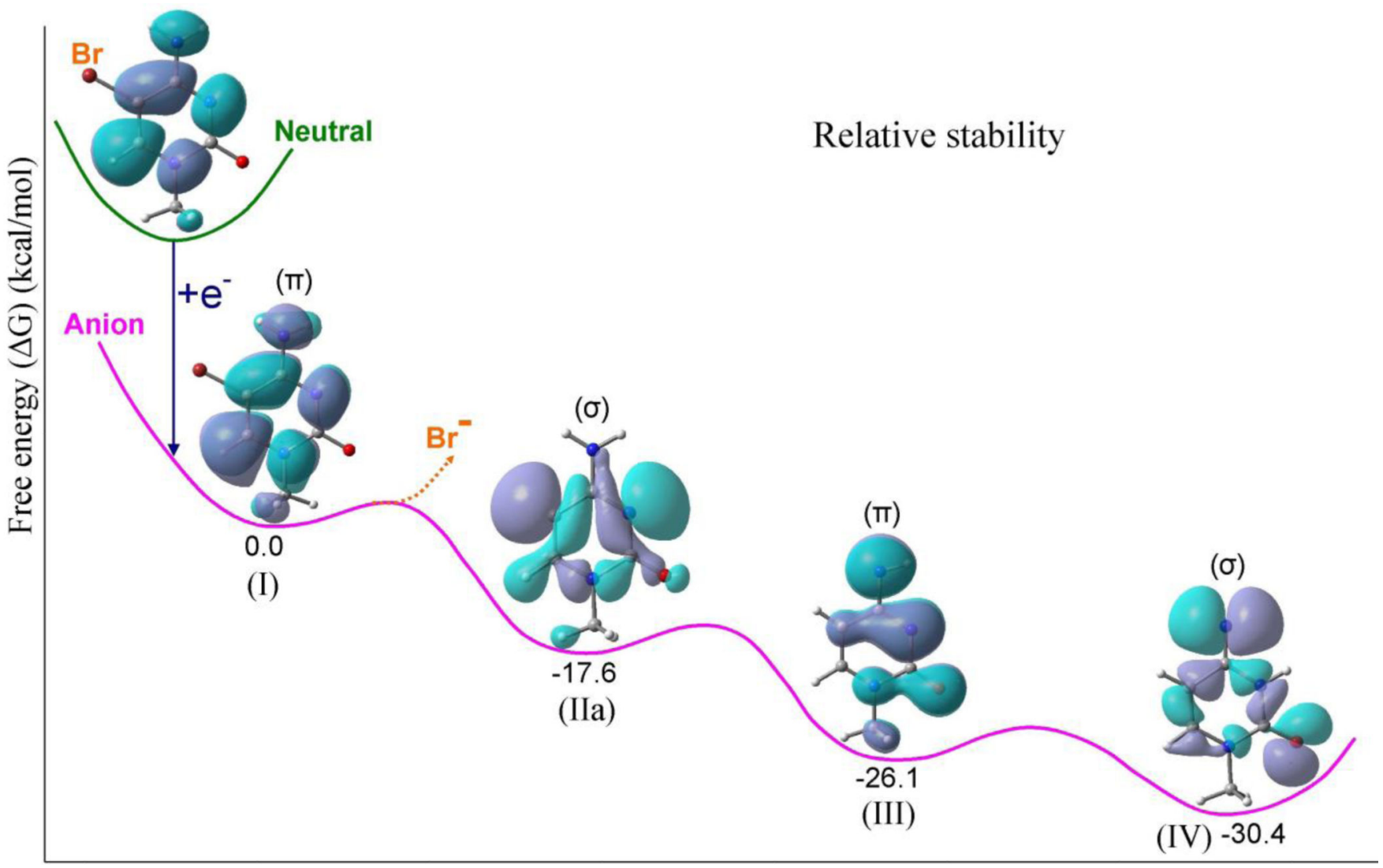

Figure 3.

Gaussian 4 calculated relative thermodynamic stabilities of radicals after an electron addition to 5-Brcyt. The G4(PCM) free energy of $\mathrm{Br}^{-}$was added to the free energy of debrominated-radicals (IIa - IV) for the calculation of the relative stabilities with respect to 5-Brcyt radical anion. Relative free energies in $\mathrm{kcal} / \mathrm{mol}$ are shown below each figure. For neutral 5-Brcyt LUMO (lowest unoccupied molecular orbital) is shown which is available for electron attachment. On anion surface, SOMO (singly occupied molecular orbital) is shown. 
<smiles>[R]n1c([2H])c(Br)c(NCC)nc1=O</smiles>

( $\pi)$

I

$\mathrm{R}=\mathrm{CH}_{3}$<smiles></smiles>

$(\sigma)$

II<smiles>[R]n1c([2H])c[14c](N)nc1=O</smiles>

$(\sigma)$

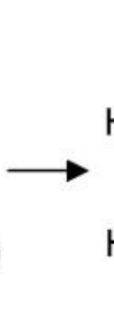

IIa<smiles></smiles>

( $\pi)$<smiles>[R]n1c([2H])c([2H])c(=N)[nH]c1=O</smiles>

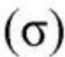

III

\section{Scheme 1.}

Proposed mechanism of iminyl radical (IV) formation by one-electron reduction of 5-Brcyt. 


\section{Table 1}

Relative stabilities $(\Delta \mathrm{G})$ of radicals formed by electron attachment to 5-Brcyt in $\mathrm{kcal} / \mathrm{mol}$ using different methods (all with PCM). The transition state (TS) for debromination of 5-Brcyt anion radical calculated by various DFT methods are given in $\mathrm{kcal} / \mathrm{mol}$.

\begin{tabular}{|c|c|c|c|c|}
\hline \multirow[t]{2}{*}{ System $a$} & \multicolumn{4}{|c|}{ Relative stability $\Delta \mathbf{G}(\mathrm{kcal} / \mathrm{mol})$} \\
\hline & G4-theory & B3LYP $^{b}$ & $\omega \mathrm{b97} \mathrm{x}^{b}$ & M06-2x ${ }^{b}$ \\
\hline 5-brCyt (EA of Neutral) & $2.27 \mathrm{eV}^{c}$ & $2.25 \mathrm{eV}^{c}$ & $2.23 \mathrm{eV}^{c}$ & $2.16 \mathrm{eV}^{c}$ \\
\hline (I) 5-brCyt (Anion radical) & 0.0 & 0.0 & 0.0 & 0.0 \\
\hline$(\text { III })^{d}$ & & -14.45 & -10.64 & -11.43 \\
\hline$(\mathrm{IIa})^{e}$ & -17.58 & -14.65 & -7.48 & -9.10 \\
\hline (III) $^{e}$ & -26.10 & -25.00 & -16.93 & -16.88 \\
\hline$(\mathrm{IIII})^{e}$ & 7.22 & $9.11^{d}$ & -0.21 & -1.49 \\
\hline$(\mathrm{IV})^{e}$ & -30.35 & -26.4 & -21.07 & -20.47 \\
\hline $\operatorname{TS}\left(\Delta \mathrm{G}^{\#}\right)$ & - & 1.79 & 7.17 & 4.32 \\
\hline
\end{tabular}

${ }^{a}$ See Scheme 1 and Figure 2 for species number.

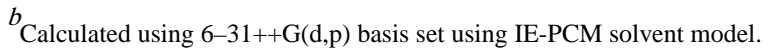

${ }^{c}$ Adiabatic electron affinity (AEA). AEA $=$ Neutral - Anion

${ }^{d}$ Loosely bound complex. See Figure 1.

${ }^{e}{ }_{\Delta \mathrm{G}}$ of $\mathrm{Br}$ anion added to debrominated-radicals, structures shown in Figure 2, for calculation of the relative stabilities with respect to (I). 